\title{
ENSINO DE LÍNGUA PORTUGUESA: RENOVANDO AS PRÁTICAS ESCOLARES E INSERINDO O ALUNO EM SEU PROCESSO DE FORMAÇÃO
}

Ediene Pena Ferreira ${ }^{1}$ Joelma Sá Figueiredo ${ }^{2}$

\begin{abstract}
Resumo: Este trabalho teve como objetivo analisar e descrever o resultado do processo de ensino aprendizagem de língua portuguesa, utilizando a proposta metodológica de Castilho (2014). Para isso, elaborou-se um projeto de intervenção executado com alunos do primeiro ano do ensino médio. A pesquisa caracteriza-se como abordagem qualitativa, e como instrumento de coleta de dados foi utilizado o diário de bordo e a observação participante. Os sujeitos participantes da pesquisa foram alunos do $1^{\circ}$ ano do ensino médio de uma escola pública de Santarém-PA. O resultado da pesquisa mostra que a inovação da prática pedagógica é essencial ao desenvolvimento do aluno e que a proposta de Castilho consegue inserir o aluno em seu processo educativo levando-o à formação de um pensamento crítico sobre sua língua.
\end{abstract}

Palavras-chave: Língua portuguesa. Língua falada. Prática pedagógica. Consciência linguística.

\section{PORTUGUESE LANGUAGE TEACHING: RENEWING SCHOOL PRACTICES AND INSERTING THE STUDENT INTO ITS TRAINING PROCESS}

\begin{abstract}
This study aims to analyze and describe the result of the teaching process of learning grammar, using the methodological proposal of Castilho (2014). To this end, an intervention project was developed with students in the first year of high school. The research is characterized as a qualitative approach, and as a data collection instrument, the logbook and participant observation were used. The subjects participating in the research were students from the first year of high school at a public school in Santarem-PA. The result of the research shows that the innovation of pedagogical practice is essential to the student's development and that Castilho's proposal manages to insert the student in his educational process leading him to the formation of a critical thought about his language.
\end{abstract}

Keywords: Portuguese language. Spoken language. Pedagogical practice. Linguistic awareness.

\footnotetext{
1 Professora da Universidade Federal do Oeste do Pará (UFOPA). Doutora em Linguística pela Universidade Federal do Ceará (2007), com estágio de doutoramento na Faculdade de Letras da Universidade de Lisboa (Portugal). E-mail: edienepenaferreira@gmail.com

2 Mestre em Letras pela Universidade Federal do Oeste do Pará (UFOPA). E-mail: joelma.figueiredo@ufopa.edu.br
} 


\section{INTRODUÇÃO}

Este trabalho - parte de um projeto de intervenção, realizado no âmbito do Programa de Mestrado Profissional em Letras/ProfLetras - tem por objetivo contribuir com a discussão sobre o ensino de língua portuguesa, por meio da aplicação de uma proposta metodológica que proporcione a análise e a reflexão da língua em textos falados e escritos significativos para os alunos, inserindo a língua falada nas atividades diárias de ensino de língua portuguesa de modo que os alunos alcancem a condição de falantes pensantes e críticos em sua língua.

Nossa proposta nasce da necessidade de se repensar o ensino de língua. Britto (1997), ao fazer crítica ao ensino tradicional da língua portuguesa, destaca que a escola, ao se preocupar com o ensino de determinada teoria gramatical e sua respectiva metalinguagem e a valorização absoluta de uma modalidade linguística no ensino, fez com que fosse esquecido o que é fundamental no exercício da língua: o texto. E que trazê-lo de volta significa pensar a língua em suas condições efetivas de uso. Nessa perspectiva, ensinar a gramática seria pensar a língua como é usada e avaliada pela sociedade.

Com a preocupação de não privilegiar a modalidade escrita, já tão privilegiada no contexto escolar, propomos atividades atribuindo protagonismo à modalidade falada e ao aluno, que passa a ser inserido no processo de formação. Para tanto utilizamos a proposta metodológica de Ataliba de Castilho explicitada em seu livro "A língua falada no ensino de Português" (2014) com o objetivo de analisar o resultado do processo de ensino aprendizagem da gramática da Língua Portuguesa falada e escrita.

Pretendemos como isso, despertar, no aluno, o interesse pela reflexão e análise sobre os fatos linguísticos e fazer com que o professor revise sua prática de ensino e reconheça que, se o trabalho que vem sendo realizado, utilizar apenas a gramática tradicional, os objetivos propostos de ensino de língua portuguesa não serão plenamente alcançados.

$\mathrm{Na}$ seção 1, resumimos a proposta que serve de base para nossa pesquisa; na seção 2, apresentamos os procedimentos metodológicos; na seção 3, descrevemos e analisamos o projeto de intervenção. Encerramos o texto com algumas considerações sobre a aplicação da proposta.

\section{RESUMINDO A PROPOSTA DE CASTILHO (2014)}

Este trabalho - uma proposta de intervenção para o ensino de língua - foi realizado tendo por embasamento o livro A língua falada no ensino de Português, de Ataliba Teixeira de Castilho (2014). O autor apresenta, nessa obra, uma proposta de aula, orientando o professor como trabalhar a língua falada no ensino médio. Para isso, Castilho faz uma reflexão sobre a Análise da Conversação e sua aplicação na sala de aula. Para melhor compreensão de nossa proposta, apresentaremos, a seguir, o resumo da obra.

Castilho apresenta, na introdução, A Teoria Modular, segundo a qual as línguas naturais compõem-se de três módulos (discursivo, semântico e gramatical), interligados pelo léxico. O módulo discursivo compreende aquilo que diz respeito às negociações entre os sujeitos implicados na situação de enunciação. $O$ módulo semântico suporta tudo o que se refere ao sentido. O módulo gramatical concentra as noções de fonologia, morfologia e sintaxe. A proposta metodológica está dividida em três momentos: "a conversação", "o texto" e "a sentença":

Ao falar sobre a conversação, Castilho orienta o professor como iniciar o trabalho com um corpus de língua falada, detalha sobre os princípios básicos e os tipos de conversação e explica por que esta é 
considerada uma atividade dinâmica. Traz sugestões para se obter um corpus falado, indicando como primeiro passo a gravação livre de uma conversa, surpreendida na própria escola, ou fora dela. E apresenta dicas valiosas sobre transcrição para os corajosos professores aventureiros na mata "quase virgem" da conversação.

Em seguida, destaca pontos fundamentais da Análise da Conversação: a) turnos conversacionais; b) manutenção do turno; c) passagem de turno acontece pelo "assalto ao turno" ou por passagem consentida de turno. Castilho também sugere que se detalhe e analise com os alunos o sistema de correção e os pares adjacentes.

Há destaque especial aos marcadores conversacionais (MCs), que verbalizam o monitoramento da fala. São vazios de significado, mas relevantes para a manutenção da interação. Castilho sugere que o professor, considerando a realidade de seu aluno, elabore um quadro dos marcadores conversacionais, para que se destaque os marcadores sociais, os marcadores sulistas, nortistas.

Ao falar sobre o texto, o autor chama atenção para os movimentos que o constroem: de ativação, de reativação e de desativação. Para Castilho, os falantes utilizam, em uma situação de interação, simultaneamente, os módulos discursivos, semânticos e gramatical, mediados pelo léxico, formando textos, por meio dos movimentos de ativação, reativação e desativação das propriedades semânticas e gramaticais do léxico.

A construção do texto por ativação pressupõe o conhecimento que o turno é a unidade de conversação e que a unidade do texto falado é a Unidade Discursiva, que corresponde ao parágrafo na língua escrita. Para analisar essa unidade e consequentemente como o próprio texto é constituído, devemos considerar os seguintes aspectos: (1) as unidades discursivas, (2) a hierarquia tópica, (3) os conectivos textuais.
Para análise e identificação das unidades discursivas (UDs), primeiramente, estabelecese o critério semântico que será utilizado, pois a identificação das UDs corresponde a uma compreensão do texto, dentre outras possíveis. $\mathrm{O}$ sentido das palavras deve ser observado, bem como a significação das sentenças e das significações discursivas.

Vencida essa etapa, o professor deve utilizar o texto com os alunos verificando os tipos textuais (narrativas, descritivas, dissertativas). Algumas perguntas devem ser feitas para reflexão do aluno: a) cada tipo desses não teria algum correlato gramatical? Qual o papel das UDs na construção e organização textual? Cada UD é um tópico gramatical?

Com o texto também é possível mostrar aos alunos a hierarquia tópica. Mostrar que as informações não são novas o tempo todo, pois não falamos apenas para dar ou receber informações, mas sim estabelecer algum tipo de relação, corrigir o outro, repetir coisas já ditas, procedendo a desvios temáticos.

Ainda sobre a hierarquia tópica do discurso, os alunos devem ter conhecimento de que as informações podem ser denominadas frásticas (informar, emitir sinais verbais, fazer compreender) que possuem relevância tópica ou parafrásticas (parafrasear, alterar o sentido, comentar) que possuem relevância interacional.

É importante também mostrar ao aluno como, no texto, as partes são interligadas. Para essa conexão existem os conectivos textuais, que são marcadores conversacionais cuja função é organizar o texto, mesmo não sendo obrigatórios. As UDs podem vir interligadas por justaposição ou por conexões.

Já a construção do texto por reativação é mais notável nos textos falados que nos textos escritos. É uma reconstrução em que retomamos as palavras principais e as usamos novamente no 
fluxo do texto. Esse processo pode ocorrer de duas maneiras, pela (1) repetição e pela (2) paráfrase. A repetição serve, além de conectar, enfatizar elementos da sentença, sintetizar e realocar no foco detalhes de uma narrativa.

A paráfrase, por sua vez, é um processo constitutivo da linguagem, um mecanismo de produção diversificada do discurso na situação social. Através da paráfrase, o falante escolhe um ponto de vista sobre a realidade tanto no nível da representação conceptual como no nível da verbalização. A amplificação, a metáfora e a comparação são modalidades da paráfrase. A paráfrase pode ser estudada de uma perspectiva conversacional ou de uma perspectiva textual, a proposta visa a análise na perspectiva textual.

A construção do texto por desativação acontece quando palavras principais são abandonadas e substituídas por outras, desviandose a estrutura temática. Esse processo dá origem a dois fenômenos: digressão e os parênteses.

As digressões são processos constitutivos do texto falado e podem ser de três tipos: baseadas no enunciado (representa um desvio tópico); baseadas na interação (desvio motivado por comentário feito a uma situação nova, surgida durante a conversação) e sequências inseridas (guarda relações tanto com o que vinha sendo dito, quanto com a situação que circunda os locutores).

Os parênteses não se constituem num tópico desviante, como a digressão. Eles são atos de fala que constituem pequenos esclarecimentos, comentários, perguntas, fornecendo informações rápidas ao Tópico que vem se desenvolvendo. Para apresentar o Tópico e mostrar como se constroem e progridem os textos na modalidade falada, Castilho ponta ser necessário discutir a Teoria da articulação Tema-Rema.

Entender o texto como resultado dos processos de construção: ativação, reativação e desativação de palavras principais, já é um repertório razoável de questões para serem analisadas na organização interativa do texto. Mas como o professor pode trabalhar a sintaxe? Para Castilho, o professor deve apresentar aos alunos primeiramente os processos de criação da sentença. Castilho apresenta um plano sistemático de observação da sentença, formulando quesitos a partir dos processos discursivos-computacionais de ativação, reativação e desativação já citados anteriormente. A Construção sentencial por ativação decorre da ativação das propriedades gramaticais do verbo, então deve-se observar o funcionamento dos verbos, por isso, a sugestão é que se analise (1) a escolha do verbo, (2) a organização da estrutura argumental da sentença, (3) a adjunção.

$\mathrm{Na}$ construção sentencial por reativação, durante uma conversa, é normal retomar algo já dito e ficar repetindo expressões por razões pragmáticas, como a necessidade de manter o turno, por exemplo. Como o objetivo aqui é valorizar o conhecimento linguístico dos falantes, como se revela em sua fala, é interessante examinar as transcrições gramaticais livres dos preconceitos linguísticos.

$\mathrm{Na}$ construção da sentença por desativação, o falante escolhe um verbo, e ativa nele a propriedade da transitividade, selecionando nomes ou pronomes argumentais e não argumentais, compondo assim a sentença. Um componente computacional acarreta a reativação ou desativação dessas propriedades. Ocorrem: Desativação do núcleo do predicado; Desativação do argumento externo; Desativação dos argumentos internos. Identificar as razões que levam a essas ocorrências pode levar a grandes discussões com os alunos, pois gramática é debate, não decoração de regras.

Observando as sentenças, é possível concluir que estas constituem único ato de fala e que há uma relação de dependência entre elas. Diremos, ao aluno, que elas constituem estruturas dependentes 
ou subordinadas. Em textos escritos ou falados, é possível mostrar aos alunos as estratégias de coordenação (Conjuntiva ou aditiva - o que é dito no primeiro termo, vale para o segundo; Disjuntiva on alternativa - o que é dito para o primeiro termo não vale para o segundo; e Contrajuntiva ou adversativa - o que é dito na segunda sentença contraria as expectativas da primeira) e de subordinação.

É importante ressaltar que a proposta metodológica objetiva restituir as reflexões gramaticais ao seu lugar de origem, ou seja, que elas se desenvolvam juntamente com os estudos da interação conversacional e do texto que daí resulta, por isso que a modalidade falada foi eleita para esta proposta.

Outra questão importante na proposta de Castilho é o fato de apresentar pontos de vista diferentes sobre o mesmo assunto-conteúdo, dando a possibilidade de escolha, ao professor, por aquela abordagem que mais lhe agradar e lembra ainda, que no momento da prática em sala de aula, o professor e seus alunos devem ser seus "gramáticos preferidos". E ainda, a proposta refere-se ao ensino emancipatório, em detrimento dos tradicionais "pontos de gramáticas", das fórmulas prontas. A proposta metodológica mostra-se bastante eclética nas teorias utilizadas, característica muito valorizada por Castilho no que se refere aos professores.

Para finalizar, podemos assim resumir a proposta de Castilho:

[...] a proposta (i) valoriza o educando, tomando sua própria linguagem como ponto de partida para as reflexões, (ii) muda a relação professor-aluno, transformando as aulas em momentos de descoberta científica [...] (iii) coloca o texto como ponto de partida, de que a sentença será o ponto de chegada, e (iv) divulga achados sobre a Língua Portuguesa constantes de pesquisas recentes, e, mais que tudo (v) liquida de vez a mania redutora e excludente de resumir as aulas de português a uma questão de certo/errado. (CASTILHO, 2014 p. 145).

\section{$\begin{array}{llllllllllllll}P & R & O & C & E & D & I & M & E & N & T & O & S\end{array}$ METODOLÓGICOS}

Este trabalho de intervenção se propôs a aplicar a proposta metodológica de Castilho exposta acima para, em seguida, analisar o resultado desta aplicação no ensino da língua portuguesa, considerando a linguagem (falada e escrita) do aluno.

A aplicação foi realizada com todos os alunos da turma de $1^{\circ}$ ano $\mathrm{B}$ do Ensino Médio do turno da tarde da Escola Estadual de Ensino Fundamental e Médio Professora Onésima Pereira de Barros, localizada no Bairro da Liberdade da cidade de Santarém-PA. A escolha se deve aos baixos índices de desempenho dos alunos dessa escola nas provas oficiais (Enem e Prova Brasil).

A escolha da turma de $1^{\circ}$ ano do Ensino Médio se justifica pelo fato de os alunos estarem iniciando um novo "estágio" de ensino e ansiosos por novos conhecimentos, pela novidade, pela mudança - a proposta traz mudanças significativas na maneira de trabalhar a Língua Portuguesa na sala de aula; outro ponto é a importância para a proposta metodológica que os alunos já conheçam as classes gramaticais, como afirma Castilho (2014, p. 34).

Consideramos relevante destacar, novamente, que a fala e a escrita são duas formas de realização de um mesmo sistema linguístico: a Língua Portuguesa. Uma modalidade não é superior a outra, nem uma é derivada da outra. Entendemos que a escola deve valorizar a modalidade falada, sem, no entanto, desconsiderar a linguagem escrita como afirma Neves (2014, p. 93):

Cobra-se que a escola valorize a língua falada? Sim, mas isso não pode implicar redução do papel que tem a escola no tratamento da língua escrita: apenas é lícito cobrar a restauração 
do equilíbrio que o uso linguístico tem, mas a escola desconhece: numa sociedade letrada não se escreve e se lê apenas, também (e principalmente) se fala.

Pelos motivos já expostos, objetivamos nesta pesquisa a) verificar se o trabalho com gramática em uma perspectiva aberta, criativa, indagativa, formativa, de formalização, de percepção da língua é eficiente, funciona, produz, gera resultados positivos; b) caracterizar que aluno se estaria formando com a mudança de perspectiva de ensino, ou seja, ao aplicar a proposta de Castilho; c) avaliar se o ensino aberto de língua, proposto por Castilho, tem como consequência a abertura do pensamento, da consciência linguística e metalinguística; d) relacionar as dificuldades/facilidades encontradas na aplicação da proposta metodológica de ensino de gramática de Ataliba de Castilho; e) verificar a opinião do aluno sobre o ensino tradicional de língua e o ensino proposto por Castilho; f) discutir a importância de trabalhar a gramática da língua falada na sala de aula.

\subsection{Da pesquisa e coleta de dados}

A pesquisa de campo foi realizada numa abordagem qualitativa, utilizando a sala de aula, onde foram ministrados por mim 20 (vinte) encontros-aulas de Língua Portuguesa que foram embasados na proposta de Castilho. É importante observar que a proposta foi aplicada durante todo o ano letivo de 2016, mas, para este trabalho foram considerados apenas os vinte primeiros encontros (trinta e quatro horas/aulas), devido à limitação de páginas.

Após a apresentação do projeto e aprovação pelo corpo administrativo, técnico pedagógico e discente da escola, foi solicitado aos alunos à assinatura no Termo de Consentimento para as gravações em áudio e vídeo de conversas livres deles que estão sendo utilizadas como corpus da língua falada. Estas conversas foram transcritas e incorporadas nas aulas de gramática, conforme orienta Castilho (2014, p. 21):

\begin{abstract}
O ponto de partida para a reflexão gramatical será o conhecimento linguístico de que os alunos dispõem ao chegar à escola: a conversação. [...] A proposta se fixa na língua que adquirimos em família, como um ponto de partida mais autêntico. Com ela nos confundimos, e nela encontramos nossa identidade.
\end{abstract}

Considerando a importância da pesquisa, para levantamento e coleta de dados utilizamos a observação participante,

\begin{abstract}
A Observação Participante pode ser considerada parte essencial do trabalho de campo na pesquisa qualitativa. Sua importância é de tal ordem que alguns estudiosos a tomam não apenas como uma estratégia no conjunto da investigação, mas como um método em si mesmo, para compreensão da realidade. (MINAYO, 2014, p. 273)
\end{abstract}

O desenvolvimento dos trabalhos se realizou por meio de pesquisa-ação por se tratar de uma metodologia muito utilizada em projetos de pesquisa educacional em que os envolvidos são direcionados a produzirem conhecimentos de forma cooperativa e participativa e a se tornarem os sujeitos dessa produção.

\subsection{Das atividades na sala de aula}

O ensino de Língua Portuguesa na sala de aula parece estar quase que totalmente direcionado para a escrita, ao passo que a oralidade é relegada para um segundo plano ou simplesmente é desconsiderada como "matéria de ensino". Com raras exceções são desenvolvidas atividades que exploram a língua falada do/no aluno. Quando muito, fica somente nas leituras em voz alta, em que não há a participação de todos os alunos e muito menos pode ser considerada uma atividade significativa para o desenvolvimento da linguagem falada. 
O homem é um ser social que utiliza a linguagem no seu dia a dia e em todo momento se depara com situações em que é necessário usar a linguagem de maneiras diferentes em diferentes situações. Por esse motivo, nas aulas de língua portuguesa, o professor precisa proporcionar ao aluno o convívio com variadas práticas, valorizando, portanto, as duas modalidades da língua como afirma Castilho.

[... No caso particular da Língua Portuguesa, não se acredita mais que a função da escola deva concentrar-se apenas no ensino da língua escrita, a pretexto de que o aluno já aprendeu a língua falada em casa. Ora, se essa disciplina se concentrasse mais na reflexão sobre a língua que falamos, deixando de lado a reprodução de esquemas classificatórios, logo se descobriria a importância da língua falada, mesmo para a aquisição da língua escrita. (CASTILHO, 2014 p.13)

Éimprescindível que o professor compreenda a importância de se trabalhar a modalidade falada da língua e utilize práticas pedagógicas que contribuam para a inclusão do aluno no meio social, para atingir objetivos mais amplos e relevantes no ensino da língua portuguesa que é favorecer um contato mais positivo do aluno com a língua que ele estuda, a fim de que saiba falar, ouvir, escrever e ler mais adequada e competentemente.

Desta forma, o professor conseguirá, também, aproximar-se de "seu perfil ideal: o de contribuir significativamente para que os alunos ampliem sua competência no uso oral e escrito da língua portuguesa", nas palavras de Antunes ( 2003, p.14), pois sem a adequação sociolinguística do uso nestas modalidades, um falante-ouvinte não é completamente competente para se comunicar em situações sociais diversas.

Em vista do exposto, o material que foi utilizado para o ensino de gramática na escola, considerando as duas modalidades da língua e embasado na proposta metodológica de Castilho, teve como ponto de partida o conhecimento linguístico que o aluno já possuía, adquirido no seu contexto familiar, por isso, o corpus para a reflexão e análise gramatical foi a própria fala do aluno, ou seja, a conversação. O ponto de chegada foi o trabalho com o conhecimento linguístico "do outro", com a análise de textos escritos de interesse práticos e de textos literários.

As atividades, organizadas em encontrosaulas, apresentam observações para informação do professor e também observações para orientação do aluno pelo professor.

As atividades de análises e reflexões da linguagem escrita e falada foram apoiadas em recursos como: a fala do aluno transcrita; vídeos de discursos políticos, entrevistas; curta metragem; cenas de novelas e filmes com diálogos; apresentação de jornal na televisão; conversa telefônica, causo, conto e memórias literárias.

Foram realizados questionamentos (perguntas referentes aos assuntos das aulas) que servirão para verificar a competência adquirida pelo aluno. Foi também elaborado um quadro regional e/ou estadual com os marcadores discursivos brasileiros mais usados.

A variedade de recursos utilizados nas atividades encontra explicação na intenção de levar o aluno a observar o uso da língua em diversas formas de apresentação do texto falado/escrito, formal/informal e suas estratégias de textualização específicas. Tudo isso para contribuir com o aumento da capacidade de um pensamento crítico sobre a língua.

Por fim, com uma produção final (ao final de cada encontro) o aluno teve a oportunidade de pôr em prática o que aprendeu com as atividades desenvolvidas; de verificar o que aprendeu e o que fazer com isso; de regular e controlar seu comportamento de produtor de texto oral e escrito revisando e reescrevendo. E o professor pode fazer uma avaliação somativa, verificando se o aluno fez uso do que foi ensinado. 


\section{O PROJETO: APLICAÇÃO ANÁLISE \\ Nesta seção, serão descritas a implementação do projeto na escola, as primeiras atividades, a repercussão entre os alunos e a análise das atividades.}

\subsection{Primeiras impressões}

Com objetivo de apresentar o projeto aos alunos e gravar a fala (conversação) deles, foram realizados dois primeiros encontros-aula (seis horas/aulas de quarenta e cinco minutos) utilizando a proposta de Castilho. $\mathrm{Na}$ apresentação do projeto, alguns alunos demonstraram apreensão porque sua conversação teria que ser gravada em áudio e vídeo. Foi explicada a importância da língua falada e a importância do trabalho.

Considerando que a proposta de intervenção tem como ponto de partida o conhecimento linguístico do aluno, como afirma Castilho (2014, p. 21), "a escola deve iniciar o aluno valorizando seus hábitos culturais, levando-o a adquirir novas habilidades desconhecidas de seus pais". A primeira atividade foi apresentação do filme Anjos do Sol3 cujo assunto aborda sexo, pedofilia e prostituição na infância/juventude para que o tema do filme fosse utilizado nos debates com os alunos, esses debates (conversação) foram gravados em áudio e vídeos.

Depois de assistirmos ao filme, a turma foi dividida em 06 (seis) grupos e foi solicitado aos que iniciassem uma conversa sobre o filme. Em seguida, cada grupo selecionou 01 (um) aluno para "debater" sobre o filme. O debate, que foi gravado estava programado para ocorrer entre dois alunos de cada vez, pois facilitaria no momento da transcrição das falas. Mas, por sugestão dos alunos 3 Filme brasileiro de Rudi Lagemann.
E fizemos o debate entre os seis alunos de uma só vez.

Para iniciar as discussões foram feitas perguntas como: Você gostou do filme? Por quê? Qual o tema do filme? Esse tema acontece na vida real? Conte um fato relacionado ao tema. Por que você acha que isso acontece na vida real? Qual conselho você daria para os personagens do filme?

Os alunos, quase que unanimemente, responderam que não haviam gostado do filme, pois, muitas cenas eram impactantes, violentas, mas relacionaram o filme com a vida real e relataram histórias que presenciaram ou que já tinham ouvido falar sobre as questões abordadas no filme. Quando solicitado um conselho para um personagem do filme, os alunos quiseram aconselhar os vilões da história.

Durante o debate, muitos se emocionaram e choraram, uma aluna chorou bastante e não quis participar das discussões. Depois de conversarmos com ela sobre o assunto, foi encaminhada para o serviço técnico-pedagógico da escola.

Ao final daqueles dias de aulas, foi solicitado aos alunos que gravassem seus depoimentos. Destes primeiros encontros-aula, obtivemos os seguintes depoimentos:

(01) Nossa aula foi um pouquinho dinâmica, é tipo, os professores num tem esse tipo de aula com a gente. É como se inspirasse os alunos a se abrir com toda a sala... (aluno 1).

(02) Isso ajuda bastante, uma aula bem distrativa, assim, que a pessoa se... dinâmica... que a pessoa se deixa levar pela aula... é e fica mais concentrado e pode até aprender mais do que numa aula normal. (aluno 12).

(03) É bem diferente a forma que a professora nos mostrou a aula, né? tipo nos passou o filme, a gente aprendeu um pouco, né? Debateu sobre isso e isso foi muito legal, bem diferente, no sentido bom, é isso aí. Se tiver muito dessas aulas assim, a gente vai ficar muito feliz. (aluno 10). 
(04) A gente aprende mais assim e a gente debate e discute sobre os assuntos que ocorrem e também parece que o tempo passa mais rápido... (aluno 7).

Os depoimentos mostraram que os alunos haviam gostado da aula participativa, dinâmica e que estavam muito felizes, que a proposta era diferente da que estavam acostumados desde que entraram na escola, pois podiam falar e que estavam cansados das aulas "antigas" em que só ouviam e escreviam no caderno e que já percebiam que iam gostar muito da língua portuguesa.

Esta fala dos alunos vai justamente ao encontro do que estamos pretendendo com a aplicação desta proposta metodológica para o ensino da língua portuguesa, ou seja, um trabalho conjunto da língua falada e da língua escrita para que o aluno não somente aprenda a produzir textos escritos, mas também, consiga aprender a utilizar a fala em diferentes contextos e situações sociais e pare de se sentir incapaz de usar sua língua por medo de falar errado.

Sobre esta questão, Neves (2014, p. 90) argumenta,

\begin{abstract}
Acredito que, na conclusão, a única certeza plena que se terá é a de que a escola tem que ser garantida como o lugar privilegiado de vivência de língua materna: língua falada e língua escrita, língua padrão e língua não padrã̃o, nunca como pares opositivos, ou como atividades em competições; enfim, uma vivência da língua em uso em sua plenitude: falar, ler, escrever. A escola está aí para isso, e não pode desconhecer que tal atitude passa poruma valorização - com justiça há muito requerida - da língua falada no espaço escolar.
\end{abstract}

Fica evidente, na citação, a importância da inserção da língua falada no processo de ensino aprendizagem da língua portuguesa na escola. As duas modalidades da língua não se opõem e não devem competir entre si, ambas têm valor e a escola precisa reconsiderar o trabalho que vem sendo desenvolvido utilizando somente a língua escrita.
Outro ponto importante, destes primeiros encontros, são as gravações. Ficou muito claro que os alunos não demonstraram tanta espontaneidade, não foram tão naturais, ou seja, eles procuraram adequar sua fala de acordo com a tradição gramatical. Analisando esse fato, fica evidente que os alunos consideram que existe uma forma de linguagem que é melhor que a outra, por isso, a maioria dos alunos da turma, embora nos grupos estivessem participando ativamente dos debates, no momento em que percebiam que estavam sendo gravados, paravam de falar porque "falavam errado". Sobre isso, Possenti (2012, p. 52) afirma

E é preciso dizer, com todas as letras, que todas as variedades são boas e corretas, e que funcionam segundo regras tão rígidas quanto se imagina que são as da "língua clássica dos melhores autores".

As variedades não são erros, mas diferenças. Não existe erro linguístico. $O$ que há são inadequações de linguagem, que consistem não no uso de uma variedade, em vez de outra, mas no uso de uma variedade em vez de outra numa situação em que as regras sociais não abonam aquela forma de fala.

\subsection{A conversação: identificação de marcadores discursivos e tópicos discursivos ou sentenças temáticas}

Dando prosseguimento à aplicação da proposta de intervenção, desenvolvemos mais três encontros-aula (seis aulas de quarenta e cinco minutos) com objetivo de transcrever as falas gravadas e identificar os marcadores discursivos MDs (orientados para o texto e orientados para o falante) e os tópicos discursivos ou sentenças temáticas (núcleo). Por isso, assistimos ao vídeo e ouvimos as falas gravadas observando o caráter interacional do texto. 
Destacam-se os momentos em que os alunos se viam nos vídeos (foram muitas risadas) e eles mesmos comentavam que o colega queria "falar bonito", outros queriam que suas apresentações fossem apagadas para gravar de novo porque "não tinham falado direito" ou porque "falaram errado".

Novamente se evidencia a questão do certo e do errado na língua, que ainda é uma constante na escola e na sociedade em geral, favorecendo a discriminação das pessoas que não utilizam a linguagem padrão e fazendo com que acreditem que não sabem falar o português correto. Veja o que afirma Geraldi (2010, p. 36) sobre esse assunto

\begin{abstract}
Habituados a observar as diferenças, nosso olhar para as variedades linguísticas tem esquecido, não raras vezes, que todos os dialetos são resultados do trabalho coletivo. Que muito da "linguagem popular" contém a linguagem culta. Que esta (resultante, aliás, do latim não culto) contém muito da "linguagem popular". Não há fronteiras determinadas, explícitas. E não poderia deixar de ser assim: se a língua vai-se constituindo nos inúmeros processos de interação, é de sua natureza ser vária.
\end{abstract}

Antes de iniciarmos as transcrições da conversação, fizemos uma discussão sobre variedade linguística e refletimos a partir dos seguintes questionamentos: o que são variedades linguísticas? quem são as pessoas que falam a linguagem culta? e as pessoas que falam a linguagem popular? por que a linguagem culta é mais valorizada? pode-se mesmo utilizar em qualquer situação a linguagem culta? qual a origem da língua portuguesa?

Os alunos afirmaram que já haviam ouvido falar em variedade linguística, que se tratava das diferenças entre os falares regionais, citaram exemplos que ouvimos sempre "aqui falamos tangerina e no Sul mexerica", "falamos macaxeira e em outras partes aipim e mandioca", entre outros. Também afirmaram que "são os ricos que falam a linguagem culta e que por isso é mais valorizada e a linguagem popular é falada pelos pobres por isso menos valorizada". Que é "muito melhor utilizar a linguagem padrão em qualquer situação porque aí a gente não erra nunca". Sobre a origem da língua portuguesa eles não tinham conhecimento.

Considerando as respostas dos alunos aos questionamentos, observamos crenças e preconceitos que precisavam ser desmitificados sobre língua. Por isso, foi iniciada uma discussão com objetivo de que os alunos começassem a perceber que as variedades linguísticas constituem uma língua e que variação linguística é uma característica inerente a todo sistema linguístico. As diferenças entre no uso da língua sejam elas regionais, sociais, de gênero são legítimas e devem ser respeitadas. É da natureza da língua possuir variedades. E de acordo com Britto (1997, p. 185)

\begin{abstract}
Em outras palavras, apesar da grande variedade de registros que compõem a fala e, até mesmo a escrita dos brasileiros - desde o oral coloquial não escolarizado até textos sofisticados, com sintaxe e léxico particulares, bem como referências e estratégias argumentativas diferentes das da fala - o senso comum reconhece e assume um nível de fala em relação ao qual os demais são vistos como errados, e, na melhor das hipóteses, variações, nível este que se toma normalmente como expressão da gramática, entendida como paradigma de correção sintática, com regras bem estabelecidas de concordância, regência, conjugação verbal etc.
\end{abstract}

O tema variação linguística não estava na programação, mas foi incluído dada a necessidade de os alunos entenderem melhor o porquê da existência de variedades linguísticas e o porquê de uma variedade ser considerada superior às outras. Além disso, a exposição sobre a origem língua portuguesa contribuiu para que os alunos compreendessem por que o português é como é.

Depois dessa inserção, seguimos o planejamento. Os alunos conheceram os marcadores discursivos e descobriram que estes são elementos que se prestam à demarcação do diálogo, à ligação entre unidades comunicativas. Marcam troca de turno, fim da elocução, correção de falhas, mudança de tópicos discursivos, sustentam o turno, 
preenchem silêncios, monitoram o ouvinte, marcam unidades temáticas, indicam início e fim de asserções, dúvidas, indagações, antecipam o que será dito, corrigem ou apagam posições anteriores, reorganizam e orientam o discurso.

Foi explicado também que existem marcadores discursivos (MDs) orientados para o texto e orientados para o falante, e que os tópicos discursivos ou sentenças temáticas centradas são o núcleo da conversação.

Como um dos objetivos da aula era fazer as transcrições da conversação gravada e já havia explicado sobre os MDs e os tópicos discursivos ou sentenças tematicamente centradas (núcleo), os alunos receberam uma folha de papel dividida em três partes (Marcadores discursivos orientados para o texto, Sentenças tematicamente centradas, Marcadores discursivos orientados para o interlocutor) e outra folha com as regras da transcrição da língua falada adaptadas do Projeto Norma Urbana Culta (NURC).

Depois de explicar como são feitas as transcrições da conversação, demos início a esta atividade. Os alunos tiveram dificuldades nessa atividade, o que é normal considerando que a estavam realizando pela primeira vez. Por esse motivo e também para agilizar os trabalhos, depois das seis aulas sem conseguir terminar as transcrições, resolvemos, as pesquisadoras, transcrever as falas.

Contudo, mesmo os alunos tendo demonstrado cansaço e um pouco de desinteresse pelas aulas de transcrições, eles já começavam a pensar sobre a sua língua, a sua fala. Nos depoimentos gravados e escritos ao final das aulas, falaram que nunca tinham percebido a importância dos MDs para que a fala não ficasse "atrapalhada" e para que o outro falante pudesse entender o que estava sendo dito e participasse também da conversação, para que a interação entre o locutor e interlocutor se efetivasse de maneira mais eficiente.

Com o propóstio de reforçar o assunto dos marcadores discursivos, fizemos uma pequena pesquisa sobre os MDs utilizados pelos falantes em outros estados do Brasil. A princípio tivemos dificuldade porque não possuíamos um banco de dados com as falas de outros estados, mas, a partir da ideia dos próprios alunos, utilizamos as redes sociais, especialmente o whatsapp e o facebook, na pesquisa.

Os alunos entraram em contato com os "amigos sociais" de outros estados e, depois de explicarem sobre os MDs, conseguiram dados para a nossa pesquisa. Conseguimos montar um quadro dos MDs por estado, como se observa logo abaixo. Notamos que os alunos haviam entendido o assunto e, além disso, estavam muito motivados para as atividades.

Quadro 1 - Marcadores Discursivos por estados do Brasil

\begin{tabular}{|l|l|}
\hline \multicolumn{1}{|c|}{ Estado } & \multicolumn{1}{c|}{ Marcadores Discursivos } \\
\hline Amapá & Eu, hein? Égua!? \\
\hline Pará & $\begin{array}{l}\text { Né! Égua!?, Tá!, Pior!, Olha! Aí..., Ok!, daí...!, Escuta aqui..., pera aí!, Disque..., } \\
\text { sei lá... }\end{array}$ \\
\hline Rondônia & Nada vê!, Eu acho... \\
\hline Roraima & Tá! Né, não!?, Viu!? \\
\hline Amazonas & Pior!, Tá!, Sabe?, Assim, Assim! \\
\hline Tocantins & Olha só! A tá! \\
\hline Alagoas & Logo, loguinho!!, Bom... \\
\hline Bahia & Oxi! Mas...!, Mas, homem! \\
\hline Ceará & Visse!, Pensa no seguinte...!, \\
\hline Rio Grande do Norte & Então, sô!, Viu?, Meu sô!, \\
\hline
\end{tabular}




\begin{tabular}{|l|l|}
\hline Paraíba & Pensa...!, Seu menino!, Tudo em riba? \\
\hline Pernambuco & Pensa só!, Homem de Deus! \\
\hline Piauí & Mar, menino!! \\
\hline Maranhão & Olha aí, tá!, sô! Entendesse? \\
\hline Sergipe & É, mermo!!, Né, mermo! \\
\hline Goiás & Êh!, Eita!, ah!, Fala sério... \\
\hline Mato Grosso & Pô!, Sei lá..., Bem... \\
\hline Mato Grosso do Sul & Pô!, bom...!, É isso aí... \\
\hline Rio de Janeiro & Sério!? Fala, mano!, Fala sério!, Tipo assim! \\
\hline Espírito Santo & Presta atenção! Presta...!, Tá meu! \\
\hline Minas Gerais & Uai!, uai sô!, Acho que.. \\
\hline São Paulo & Mano!?, tá ligado? Véio! \\
\hline Paraná & Nada! Nada, não!, Percebe? \\
\hline Rio Grande do Sul & Pa!, Ba!, Tchê!! Guri(a)! Má...! \\
\hline Santa Catarina & Hãn (som), Então...!, Assim... \\
\hline
\end{tabular}

Fonte: alunos participantes da pesquisa

\subsection{Reescrita do texto falado: comparação entre as modalidades falada e escrita}

Com a conversação dos alunos já transcrita, iniciamos mais três encontros-aula com o objetivo de reescrever o texto falado, transformando-os em texto escrito. A atividade permitiu comparar as duas modalidades da língua, identificando os recursos gráficos de que se serve a língua escrita (LE), para assinalar a coesão textual e quais recursos a língua falada (LF) movimenta para o mesmo fim, observando a extensão e a densidade informativa de unidade discursiva (UDs) na LF e de parágrafos na LE.

Conversamos com os alunos sobre a reescrita do texto falado em texto escrito para suscitar neles o interesse em observar as diferenças entre as duas modalidades de língua. Em seguida, a turma foi dividida em sete grupos para a reescritura dos textos. Cada grupo com cinco ou seis componentes (o grupo foi só referencial, a transposição textual foi feita individualmente) fez a reescritura de um dos momentos da conversação (dos debates). Antes da aula, separei as fichas das transcrições por momento e estas foram distribuídas aos grupos.
Essa atividade ocupou mais tempo do que o previsto, por isso, o nono e décimo encontros-aulas (quatro horas/aula de quarenta e cinco minutos) foram utilizados para realizar as discussões sobre as reescrituras dos textos. Destacamos que, dos trinta e dois alunos, dezessete tiveram mais dificuldade para reescrever o texto e seis alunos, mesmo com muita insistência e incentivo, não quiseram fazer a atividade, porque não se sentiam capazes. Em busca de uma explicação sobre o porquê dos alunos terem tido muita dificuldade e outros se sentido incapazes de realizar a tarefa Marcuschi (2010, p. 47) diz que

\begin{abstract}
Há nestas atividades de retextualização um aspecto geralmente ignorado e de uma importância imensa. Pois para dizer de outro modo, em outra modalidade ou em outro gênero o que foi dito ou escrito por alguém, devo inevitavelmente compreender o que foi que esse alguém disse ou quis dizer. Portanto, antes de qualquer atividade de transformação textual, ocorre uma atividade cognitiva denominada compreensão. Esta atividade, que em geral se ignora ou se dá por satisfeita ou não problemática, pode ser a fonte de muitos problemas no plano da coerência no processo de retextualização.
\end{abstract}

Considerando o que o linguista fala sobre a necessidade de compreender o texto para depois retextualizá-lo, percebemos que um grave erro havia cometido, não havíamos analisado, com 
os alunos, as questões para que eles pudessem compreender o texto, por isso esta atividade foi realizada novamente em outra aula. Notamos que as questões semânticas dos textos produzidos pelos alunos não estavam sendo trabalhadas adequadamente.

Com o objetivo de obter informações a respeito do que os alunos já sabiam sobre as diferenças entre a língua escrita e a língua falada, realizamos reflexões sobre o texto falado e o texto escrito com os seguintes questionamentos: Essa atividade de reescritura foi interessante? Por quê? Há diferença entre texto escrito e texto falado? Quais? Quais recursos gráficos de que se serve a LE, para assinalar a coesão textual? E de quais se serve a LF? O texto escrito ficou maior ou menor que o falado? Por quê?

Os alunos participaram ativamente dos debates, por isso, obtive respostas como:

(05) as diferenças é tipo quando a gente fala não precisa colocar ponto, pode usar as mãos, né... (aluno 9)

(06) ...também pode usar um olhar, minha mãe só de olhar eu já sei ... (aluno 2)

(07) ...quando grita, quando fala alto, pode falar palavrão, essas coisas, né? (aluno 3)

(08) Também tem..., tem os barulhos (sons) e gestos (mostrou os gestos, de legal, silêncio ...) que a gente pode usar... (aluno1)

(09) Agora quando escreve, aí, já é diferente, não pode usar palavrão, não pode qualquer palavra... (aluno 6)

(10) Não dá pra fazer gesto, e a gente tem que decorar tudinho da gramática pra escrever direitinho... (aluno 8)

Os alunos, em sua maioria, responderam que as diferenças entre as duas modalidades da língua são, principalmente, relativo ao uso dos gestos e expressões faciais e corporais que são muito utilizados no momento em que falamos, quanto à língua escrita, eles achavam que só iam conseguir escrever direito se "decorassem" as regras da gramática tradicional.
Destacamos as dificuldades que os alunos tiveram para responder sobre os recursos gráficos que assinalam a coesão textual na LE. Todos conseguiram perceber que o texto escrito ficou maior que o texto falado porque "no texto escrito há a necessidade escrever sobre a situação, o momento, o lugar em que ocorre o texto". Relataram que já foram corrigidos porque falaram ou escreveram errado. Referente às diferenças entre as duas modalidades de língua, Marcuschi (2010, p. 34) afirma que

\begin{abstract}
Em conclusão a estas observações, pode-se dizer que discorrer sobre as relações entre oralidade/letramento e fala/escrita não é referir-se a algo consensual nem mesmo como objeto de análise. Trata-se de fenômenos de fala e escrita enquanto relação entre fatos linguísticos (relação fala-escrita) e enquanto relação entre práticas sociais (oralidade versus letramento). As relações entre fala e escrita não são óbvias nem lineares, pois elas refletem um constante dinamismo fundado no continuum que se manifesta entre essas duas modalidades de uso da língua. Também não se pode postular polaridades estritas e dicotomias estanques.
\end{abstract}

A atividade mostrou-se profícua, porque os alunos "confessaram" (expressão utilizada por eles) que jamais haviam pensado a língua portuguesa desta maneira, sempre acharam que falavam de "qualquer jeito", porque a fala não tem organização e somente na escrita tinha organização e regras. E como esclarece Marcuschi (2010, p. 47) “a passagem da fala para a escrita não é a passagem do caos para a ordem: é a passagem de uma ordem para outra ordem", desmitificando a dicotomia entre fala - lugar do erro e do caos gramatical; e escrita - lugar da norma e do bom uso da língua.

No final da aula, alguns alunos perguntaram quando seria falado sobre gramática, porque em outras turmas a professora já havia feito as revisões das classes gramaticais e estava trabalhando as orações coordenadas. Foi um momento preocupante, até mesmo a técnica pedagógica da escola questionou sobre as reclamações dos alunos. 
Explicamos novamente o objetivo do projeto de intervenção e que os aspectos gramaticais estavam sendo contemplados na proposta.

Compreender os turnos conversacionais como unidade da conversação e princípio interacional e discutir as estratégias da conversação (manutenção do turno, “assalto" ao turno e a passagem consentida de turno) na produção de textos orais foram os objetivos do nosso décimo primeiro e décimo segundo encontros-aulas (quatro horas/aula de quarenta e cinco minutos). Os conteúdos destas aulas foram explicados e depois demonstrados com exemplos.

Para tanto, foi apresentado um vídeo, com cenas da novela o Clone (diálogo entre Said e Jade), para que os alunos observassem a língua em sua modalidade falada. Antes de iniciar a apresentação, informamos que fariam atividades sobre o vídeo e que precisavam ficar bem atentos para observarem os turnos conversacionais, ou seja, as estratégias da conversação.

Durante essa atividade, os alunos já começaram a perceber as estratégias que os falantes utilizam nos momentos de conversação, o vídeo trata de uma conversa "muito intensa entre um casal", por isso os alunos citaram que um olhar, um abaixar de cabeça, um tom mais alto da conversa, um gesto com a mão ou com o corpo são estratégias que utilizamos para manter, assaltar ou passar um turno na conversa. Conforme as falas dos alunos, destacadas a seguir:

(11) Só o olhar da Jade, com essa maquiagem toda, já diz tudo, né não... é uma estratégia, né professora? (aluno 1)

(12) Esse cara, o Said grita, a menina se cala... e abaixa a cabeça... num fala mais é nada... (aluno 2)

(13) Ela tá fazendo carinho no rosto dele, nele, e falando com ele, mas quando ele levanta a mão pra bater nela, ela se encolheu todinha, coitadinha...! (aluno 5)

Dando continuidade à aula, dividimos a turma em grupo para os alunos identificarem nos seus textos transcritos as estratégias conversacionais que eles haviam utilizados. Em seguida, para refletirmos sobre a importância dos turnos de conversação, perguntamos: Para que servem os turnos conversacionais? Quais recursos foram utilizados para a manutenção do turno e quem utiliza esses recursos? Por quê? Quem utiliza o "assalto" ao turno? Com qual intenção? E quais são os recursos utilizados? Na passagem consentida de turno, quais recursos foram utilizados? Por quê? Quem utiliza esse recurso na conversação? Há diferença entre "assalto" de turno e passagem consentida de turno? Quais?

Observamos que os alunos responderam as questões com facilidade, disseram que os turnos são "o momento, a vez de cada um falar", e apresentaram os recursos para manter, assaltar ou passar um turno na conversa, além do já citados, falaram ainda, em utilizar uma palavra que alguém falou para assaltar o turno.

No geral, os alunos entenderam o que são turnos conversacionais, pois citaram exemplos tanto do texto transcrito como do filme que havíamos assistido e até mesmo no momento das discussões foram usadas expressões como "vou assaltar o turno" e "alguém quer o turno?" Explicamos que, nem sempre, há necessidade de oferecer o turno dessa maneira, que podíamos utilizar outros recursos, como fazer uma pausa mais longa na fala, incorporar uma correção do interlocutor, entre outras. Castilho (2014, p. 228) destaca sobre a transição pacífica de um turno para o outro

Os analistas da conversação identificaram o
lugar relevante da transição, em que se processa
uma sorte de transição pacífica de um turno
para outro. Esse lugar pode ser (i) um ponto
prosodicamente definido, no final de uma série
rítmica; (ii) um ponto sintaticamente definido,
no final de uma estrutura; (iii) um ponto
culturalmente definido. O lugar relevante da
transição comprovou que, ao acompanhar uma
simples conversa, operamos simultaneamente
com vários canais, monitorando os atos
de fala: observamos a fisionomia de nosso
interlocutor, tentando interpretar sinais,
prestamos atenção à materialidade de sua fala, 
analisando sua execução fonética, gramatical e léxica, a partir de nossas práticas culturais.

Mostramos aos alunos que é dessa maneira que a conversação acontece no nosso dia a dia, falamos assim, sem, muitas vezes, nos darmos conta disso. Discutimos, ainda, que as estratégias da conversação dependem inteiramente da intenção do falante. Com objetivo de organizar melhor o momento das nossas discussões, refletimos sobre a manutenção, o assalto e as passagens de turno, nas nossas discussões, e combinamos que deveriam acontecer de uma maneira mais pacífica, sem muitas sobreposições de falas que sempre estão ocorrendo e acabam por atrapalhar o ritmo e o bom andamento das discussões.

$\mathrm{Na}$ turma há cinco alunos, sendo quatro meninos e uma menina, que sempre se destacaram por suas opiniões durante as discussões, possuem uma capacidade, que está se desenvolvendo, de análise crítica, de compreensão de questões que vão além dos aspectos linguísticos e abrangem as situações sociais, e já conseguem perceber e exemplificar as intenções nas falas de professores, apresentadores de televisão, políticos, entre outros, ao observarem a fala destes.

Esse fato nos fez perceber que o trabalho desenvolvido, embora ainda não tivesse atingido a todos os alunos da sala, já proporcionava a formação de juízo e crítica, de liberdade, de abertura do pensamento. Conforme afirma Britto (1997, p. 23),

Contrariamente ao que ocorre hoje, acreditamos que o papel fundamental da escola deve ser o permitir a emergência de sujeitos críticos, capazes de investigar, descobrir, articular, aprender, em suma, capazes de, a partir de objetos do mundo conhecidos, estabelecer uma relação inusitada entre eles. [...]. Supõe-se que, na convivência com o conhecimento formal e elaborado e na prática diária de construção de seu próprio conhecimento através da confrontação de sua experiência imediata com o saber científico, o aluno possa desenvolverse social e intelectualmente, formar juízo e crítica, experimentar a liberdade de pensamento.

Considerando tudo que Britto (1997) fala sobre permitir que o aluno construa seu próprio conhecimento e construa seu juízo de valor, experimente a liberdade de pensamento a partir da investigação, das descobertas, resolvemos aceitar a sugestão deles e decidimos analisar as intenções (implícitas) de um jornal de televisão. Dividimos a turma em grupo e essa atividade ficou para ser pesquisada em casa e apresentada em outro momento

\subsection{O sistema de correção na língua falada}

No décimo terceiro e décimo quarto encontros-aulas (seis horas/aulas de quarenta e cinco minutos), discutimos o sistema de correção, como consequência da coexistência na LF do planejamento e execução em tempo real. O objetivo era fazer o aluno reconhecer que os sistemas de correção (autocorreção, heterocorreção, correção da palavra truncada, negação de “dicto" e paráfrase) servem para reajustar/reorganizar a mensagem no momento real da fala.

Dois vídeos, retirados da internet, foram apresentados aos alunos. Um com discurso político (o candidato não consegue fazer o discurso nem lendo o papel e realiza muitas correções) e outro com uma apresentação do jornal televisivo "Cidade Alerta" (o apresentador Marcelo Resende faz muitas correções durante sua apresentação). Os alunos perceberam os sistemas de correção, em seguida, transcreveram os texto pontuando esse sistema.

Notamos que os alunos não tinham entendido muito bem os sistemas de correção. Talvez por estarem acostumados à ideia de que 
corrigir significa "consertar" os erros gramaticais (pontuação, concordância...); não conseguiram entender os sistemas de correção que fazemos uso nos momentos da fala. Houve uma grande confusão na sala.

Depois da situação contornada, explicamos novamente os sistemas de correções, colocando exemplos do nosso cotidiano e tive que repetir os vídeos, e assim os alunos começaram a entender o assunto e foi possível passar para a análise de seus textos.

A turma foi novamente dividida em grupo para os alunos identificarem nos textos os sistemas de correção utilizados. Para direcionar os alunos foram utilizadas as questões: Para que servem os sistemas de correção? Quais tipos de correção foram utilizados no texto e quem utilizou esses recursos? Com qual intenção foram utilizados os sistemas de correção? Quando utilizamos mais os sistemas de correção? Por quê? O ouvinte/ participante da conversa tem influência na utilização dos sistemas de correção? Por quê? A reação do ouvinte/participante influencia no uso dos sistemas de correção? Por quais motivos? O fluxo da conversação também influencia no uso dos sistemas de correção? Por quê? Os sistemas de correção dependem da intenção do falante, por quê?

Os alunos conseguiram responder que as correções servem para corrigir algumas palavras "mal ditas", que o falante "não queria dizer aquilo", por isso substituíam ou negavam as palavras já pronunciadas ou, ainda, faziam pausas procurando uma palavra mais adequada para a conversa e citaram exemplos tanto dos vídeos quanto de seus textos. Responderam também que as correções aconteceram para dar continuidade na conversa e que a correção acontece tanto do locutor quanto do interlocutor. E, sim, as correções dependem das intenções do falante.
Os alunos concluíram, também, ue durante a fala realizamos duas ações simultaneamente, o planejamento e execução dos textos e que por isso, nem sempre planejamos direito o que falamos, muitas vezes precisamos "corrigir" o que dissemos por vários motivos e um deles é porque a reação do interlocutor não foi a que esperávamos ou porque não estamos tendo a participação efetiva do outro na conversa.

Novamente, os alunos questionaram sobre a (des)organização na língua falada, ainda não estavam convencidos da existência de regras, de uma gramática internalizada que acionamos para falar assim como para escrever. Observe o que fala Neves (2014, p. 44),

\begin{abstract}
Obviamente o bom uso se fixou na modalidade escrita, entendendo-se a linguagem falada como território que, por menor, podia abrigar todas as tolerâncias e "transgressões", como se a língua falada não tivesse norma, quase como se não tivesse gramática. Criouse na escola, um tal abismo entre as duas modalidades que, no fundo, instituiu-se que a fala (em princípio, a modalidade do aluno) é imperfeita por natureza, e que a língua escrita (em princípio, a modalidade do professor) é a meta a ser atingida, como se não houvesse modalidade-padrão também na fala e como se o conhecimento de um padrão privilegiado, na língua falada, não fosse também desejável.
\end{abstract}

Dessa forma, consideramos relevante, mais uma vez, falar o quanto é importante que a escola reveja e reavalie suas considerações sobre a língua falada, e pare de colocar as duas modalidades de língua em competição, em oposição. E passe a olhar a língua falada com o mesmo respeito com que olha a língua escrita, percebendo sua organização e sua gramática.

Para exercitar, solicitei aos alunos que elaborassem uma dramatização (discurso político, apresentação de jornal) dando destaque aos sistemas de correção estudados. O trabalho foi apresentado oralmente. Pude destacar as seguintes falas das apresentações: 
(14) ... quero pedir seus votos, ou melhor, implorar por eles... (apresentação 1)

(15) ... hoje no bairro da Nova República, não, no bairro do Santo André.... (apresentação 2)

(16) $\mathrm{O}$ quê? $\mathrm{O}$ que foi que você disse? Me chamou de fracassado? Não, eu disse que queria frango assado... (apresentação 3). (Os alunos gostavam muito de colocar uma comédia em suas dramatizações).

No momento da preparação e apresentação dos trabalhos, já foi visível que os alunos entenderam o assunto estudado, claro que aconteceram alguns exageros no uso dos sistemas de correções.

Outras atividades também fizeram parte do projeto, mas, para os objetivos deste artigo, selecionamos apenas essas atividades para apresentação.

\section{CONCLUSÃO}

As atividades desenvolvidas foram de suma importância para o processo pedagógico, favoreceram o trabalho com menos imposição, mais autenticidade e mais objetividade. Possibilitaram a efetiva interação entre professor-alunos e alunoaluno e a compreensão da relação da prática sobre o processo de ensino aprendizagem da língua portuguesa.

Vimos a importância da aplicação de atividades metodológicas inovadoras que propiciem o desenvolvimento linguístico do aluno e para o aluno. Falta ao professor ser também um pesquisador em busca de mais conhecimentos teóricos para embasar sua prática educativa, como assegura Antunes (2003, p. 40),

Não pode haver uma prática eficiente sem fundamentação num corpo de princípios teóricos sólidos e objetivos. Não tenho dúvidas: se nossa prática de professores se afasta do ideal é porque nos falta, entre outras muitas condições, um aprofundamento teórico acerca de como funciona o fenômeno da linguagem humana. O conhecimento teórico disponível a muitos professores, em geral, se limita a noções e regras gramaticais apenas, como se tudo o que é uma língua coubesse dentro do que é uma gramática. Teorias linguísticas do uso da prosódia, da morfossintaxe, da semântica, da pragmática, teoria do texto, concepções de leitura, de escrita, concepções, enfim, acerca do uso interativo e funcional das línguas, é o que pode embasar um trabalho verdadeiramente eficaz do professor de português.

A prática pedagógica do professor não pode ser desvinculada de conhecimentos teóricos atualizados, deve, sim, estar fundamentada em teorias sólidas e objetivas. Muitos professores utilizam a falta de tempo por causa da quantidade de horas que precisam trabalhar, diariamente, para sustentar suas famílias como desculpas para não aprofundarem seus conhecimentos teóricos e acabam por utilizar somente um conhecimento, o da gramática normativa em suas aulas de língua portuguesa o que, geralmente, leva a um trabalho escolar ineficiente.

Foram perpectíveis o envolvimento e o interesse dos alunos pelas atividades na sala de aula, mas ressaltamos o livre arbítrio que eles possuem de querer participar ou não. A maior dificuldade para a aplicação da proposta foi referente à ausência de conhecimento ou conhecimento equivocado sobre as variedades linguísticas e sobre a existência de gramática e organização na língua falada. Os alunos já possuíam pré-conceitos formados de que só é correta a língua culta que as outras variedades de língua são erradas e por isso o usuário deve ser "condenado", discriminado. Por isso, durante quase todas as aulas tivemos que discutir sobre essas questões, buscando desmitificar tais conhecimentos sobre a língua.

Durante a aplicação da proposta era normal ouvir pelos corredores da escola e na sala dos professores comentários sobre a importância da língua falada e sobre o interesse dos alunos em participar das discussões nas aulas dos professores de outras disciplinas e nos eventos com dramatizações e até mesmo nos seminários. 
Em vista disso, percebo que trabalhar com essa metodologia proporciona a desenvoltura linguística, pois o aluno já consegue analisar textos falados.

Podemos concluir que a metodologia de Castilho traz uma mudança no modelo de ensino de língua imposto ao aluno, proporciona uma educação mais dinâmica, transformadora e significativa, pois, facilita a inserção do educando em seu processo de formação. Podemos afirmar, também, que a proposta metodológica é eficiente, pois produziu e gerou resultados positivos, principalmente, referentes à abertura do pensamento, à formação da consciência linguística e metalinguística.

Outro aspecto bastante significativo foi a transformação do aluno de um sujeito passivo, copiador de textos e seguidor de modelos "perfeitos" de língua, a um sujeito, efetivamente produtor de seus conhecimentos linguísticos, participante de todo o processo de ensino e aprendizagem.

O educador escolar, especialmente o professor de língua portuguesa deve sempre ser uma pessoa atenta e observadora para diagnosticar e avaliar seu trabalho em qualquer nível de ensino, e ter sempre em mente que seu "material" de trabalho é o humano.

\section{REFERÊNCIAS}

ANTUNES, Irandé Costa. Aula de Português: encontro e interação. São Paulo: Parábola, 2003.

BRITTOO, Luiz Percival Leme. A sombra do caos: ensino de língua $x$ tradição gramatical. Campinas, SP: Mercado de Letras, 1997

CASTILHO, Ataliba Teixeira de. A língua falada no ensino de Português. 8 a ed. São Paulo: Contexto, 2014.

GERALDI, João Wanderley. A aula como acontecimento. São Carlos-SP: Pedro \& João Editores, 2010
MARCUSCHI, Luiz Antônio. Da fala para a escrita: atividades de retextualização. São Paulo: Cortez, 2010 .

MINAYO, Maria Cecília de Souza. O Desafio do Conhecimento: pesquisa qualitativa em saúde. 14a ed. São Paulo: Hucitec, 2014

NEVES, Maria Helena de Moura. Que gramática estudar na escola? Norma e uso na língua portuguesa. 4a ed. São Paulo: Contexto, 2014.

POSSENTI, Sírio. Sobre o ensino de Português na escola. In: GERALDI, João Wanderley (org.). O texto na sala de aula. São Paulo: Anglo, 2012. p. 32-38.

Submissão: agosto de 2020.

Aceite: dezembro de 2020. 